\title{
Accounting Faculty mental health: coping strategies against
} stress $^{\star, * *}$

\author{
Eduardo Mendes Nascimento ${ }^{1}$ \\ (D) https://orcid.org/0000-0002-2188-9748 \\ Email: e.mn@uol.com.br \\ Marcia Carvalho Garcia² \\ (iD) https://orcid.org/0000-0001-5266-3939 \\ Email: marcia.blr@gmail.com
}

\author{
Edgard Cornacchione ${ }^{3}$ \\ (D) https://orcid.org/0000-0002-0745-131X \\ Email: edgardbc@usp.br
}

\begin{abstract}
${ }^{1}$ Universidade Federal de Minas Gerais, Faculdade de Ciências Econômicas, Departamento de Ciências Contábeis, Belo Horizonte, MG, Brazil
${ }^{2}$ Universidade Federal de São Paulo, Laboratório de Biologia do Estresse, Santos, SP, Brazil

${ }^{3}$ Universidade de São Paulo, Faculdade de Economia, Administração e Contabilidade, Departamento de Contabilidade e Atuária, São Paulo, SP, Brazil
\end{abstract}

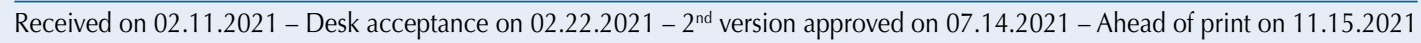

Editor-in-Chief: Fábio Frezatti

Associate Editor: Jacqueline Veneroso Alves da Cunha

\section{ABSTRACT}

This study sought to investigate which coping strategies are most frequently used by accounting faculty and how they can modulate the perceived stress. The higher education academic environment is filled with events that are stressful in nature; however, little effort, especially in the area of accounting, has been employed in seeking to understand and propose guidelines that can improve well-being and pleasure in the teaching profession. A coping strategy is a behavior that protects the individual from psychological damage related to problematic social experiences; it is through these behaviors that individuals manage their day-to-day experiences, thus helping to maintain their mental health. The discussion about the use of strategies for coping with stress lacks an approach in higher education institutions (HEIs), as it indicates that various strategies are being employed ineffectively and signals that three of the statistically significant strategies belong to the dimension of those focused on dysfunctional emotions. And, more seriously, of those three strategies, two (self-reproach and denial) have further contributed to increasing the perception of stress. The Teacher Stress Inventory (TSI), composed of 26 questions with a five-point Likert scale, and the Brief COPE (Coping Orientation to Problems Experienced Inventory), with 28 items and a four-point scale, were employed together with sociodemographic questions. An electronic questionnaire was sent to two thousand accounting faculty in Brazil. Altogether, 563 faculty members answered the questions. The analysis was conducted through association and multiple linear regression tests. It was verified that the average stress reported by the faculty members was $63 \%$ of the maximum TSI score, and the most prevalent strategies measured by the Brief COPE were planning, active coping, positive reinterpretation, use of instrumental support, self-reproach, and religion. Through linear regression estimation, it was concluded that two coping strategies (active coping and behavioral divestment) negatively moderated the faculty members' stress, but two others (self-reproach and denial) raised their perception of stress. Moreover, it was discovered that the faculty members who were most vulnerable to stress use less adaptive coping strategies more intensely.

Keywords: stress, coping strategies, accounting faculty, Teacher Stress Inventory, Brief COPE.

\section{Correspondence address}

Eduardo Mendes Nascimento

Universidade Federal de Minas Gerais, Centro de Pós-Graduação e Pesquisas em Administração, Departamento de Ciências Contábeis Avenida Presidente Antônio Carlos, 6627, Prédio FACE - CEP 31270-901

Pampulha - Belo Horizonte - MG - Brazil

*Article presented at the $20^{\text {th }}$ USP International Conference in Accounting, São Paulo, SP, Brazil, July 2020.

**The authors are grateful to the National Council for Scientific and Technological Development (CNPq) and to the Federal University of Minas Gerais (UFMG) for the financial support to carry out this research. 


\section{INTRODUCTION}

The teaching profession is one of the most exposed to confrontational environments with high work demands, involving out-of-class tasks, meetings, and additional activities, relationship problems with students (which can even include verbal and physical threats), time pressure, difficulty integrating with peers, and an accumulation of administrative activities and those involving another professional activity (Carr, 2014; David \& Quintão, 2012; Reis et al., 2005). This stressful situation can

\begin{abstract}
lead to repercussions on the teachers' physical and mental health and on their professional performance. The impact of stressful factors over professions that require specific work conditions, with a high degree of relating with the public, such as that of teachers, has been studied in other countries. (Reis et al., 2005, p. 1480, own translation)
\end{abstract}

It is thus understood that stress affects teachers' professional performance, occasionally resulting in damage to teaching practice and to their health and, consequently, in "absenteeism and requests for sick leave to treat their health, besides the depersonalized way in which the teachers start to treat the students" (Reis et al., 2005, p. 1480, own translation). In this context, by becoming chronic and persistent, stress can be understood as one of the factors that promote greater exposure of individuals, enabling states of illness and being one of the potential causes that make up biopsychosocial factors related to the understanding of the health-illness process (Santos, 2010). It is against this backdrop that coping strategies take shape.

Therefore, as not all of the circumstances that surround/compose the academic environment that give rise to stressors can be controlled, it is up to teachers to discover coping strategies that enable them to manage these difficulties and preserve their quality of life and homeostasis. This consequently contributes to maintaining a healthy organizational environment for them, their colleagues, and the students, satisfaction with their profession, and, finally, for their physical and mental health. A coping strategy is a behavior that protects individuals from psychological damage related to problematic social experiences or a behavior that mediates, in an important way, the impact that stressful events have over people (Coleman, 2019). It is through these coping behaviors or strategies that individuals manage their day-to-day experiences, which can be challenging or potentially damaging. Yet, there is no consensus in the literature about which specific coping strategies more efficiently lead to a reduction in stress, since various factors, such as cultural circumstances, social group, previous experiences, and the stressor itself, influence the choice and the result of each one of the possible coping strategies (Carver \& Connor-Smith, 2010; Folkman et al., 1986; Lazarus, 2006).

In any case, coping strategies fundamentally seek to: eliminate or modify the stressor; modify the perception about the emotional meaning in order to neutralize any negative effect; or maintain a balanced emotional state (Coleman, 2019). Thus, this study sought to investigate which coping strategies are most frequently used by accounting faculty and how they can modulate the stress they perceive.

The adverse consequences of stress can be monumental for faculty members, higher education institutions (HEIs), and students, as extreme forms of stress can lead to exhaustion, lower personal fulfillment and satisfaction, depersonalization and emotional exhaustion, an impact on academic results, including absenteeism, commitment to engage with the work, a reduction in their perception of self-efficacy, management of the faculty's well-being, and the students' learning (Carr, 2014; David \& Quintão, 2012; Embse et al., 2019; Mazon et al., 2008; Reis et al., 2005; Roeser et al., 2013; Skaalvik \& Skaalvik, 2017). Moreover, chronic stress and exhaustion, in turn, are associated with a set of personal results that are prejudicial for faculty members, even affecting their physical and emotional health, which can result in emotional disorders, associated with anxiety and depression, and physical ones, such as hypertension or even cardiovascular diseases (Carr, 2014; David \& Quintão, 2012; Mazon et al., 2008; Morimoto et al., 2019).

In particular, teacher stress and exhaustion can lead to a reduced ability to involve and teach students effectively (Clunies-Ross et al., 2008). In these terms, teacher stress and student behavior are strongly related, since while teachers report that students' behavior is a source of stress, they also manage students' behavior differently under high stress levels (Clunies-Ross et al., 2008). For that reason, teacher stress represents a significant challenge for all HEIs, given the links with a myriad of important and complex variables for explaining teachers' mental health, as well as with students' academic success and involvement (Araújo et al., 2017; Carr, 2014; David \& Quintão, 2012; Reis et al., 2005).

In sum, acute and persistent stress can damage teachers' physical and mental health, as well as their personal 
and professional well-being, ultimately compromising the teaching-learning process. Thus, understanding this event and, in particular, determining successful mitigating behavior to avoid the disorders associated with its chronic form can be an important step in reducing these undesirable and counterproductive results, given that it is essential to know which interventions can be most effective in reducing teacher stress and improving its management in adverse and tension-generating situations (Embse et al., 2019).

It is worth remembering that, in general, teachers' training and their professional development programs help them to develop stress management skills (Ferenc \& Saraiva, 2010; Roeser et al., 2013), such as regulation of emotions or attitudes such as self-control, seeking social support, positive reinterpretation, and others that they could use to deal with inherently stressful aspects of their work environments (Carver \& Connor-Smith, 2010). Thus, by listing the organizational stressors perceived by faculty members and the strategies for coping with them, it is possible to understand and interpret such events, which will enable actions in order to mitigate the adversities that give rise to maladaptations and understand the behaviors and attitudes that help in moderating teachers' mental suffering, making them resilient in the face of adversities. Moreover, this work will enable a small advancement within the context studied, considering the absence of a consensus in the literature about the strategies to be adopted in the university context (Carver \& ConnorSmith, 2010; Folkman et al., 1986; Lazarus, 2006).

Therefore, it is important to obtain more insights about how faculty experience their work, as well as how they evaluate working conditions in different phases of their careers. This observation is important, considering that working in a healthy work environment generates

benefits both for the professionals and for the organizations, through reduced absenteeism; greater employee socialization and adaptation to the organization; increased motivation; reduced errors and costs associated with productivity; increased performance and creativity; innovation; more employee interaction with their colleagues, customers, and supervisors. (Machado et al., 2012, p. 195, own translation)

\section{LITERATURE REVIEW}

\subsection{Stress}

Stress is a non-specific response of the body when faced with situations that threaten the individual's homeostasis, obliging it to mobilize resources to confront the agent causing the biopsychosocial imbalance, resulting in endocrinological responses that modify the person's homeostasis (Faro \& Pereira, 2013; Selye, 1956). In this sense, from a biopsychophysiological perspective, stress is an event perceived by the individual as a potential or systematic occurrence, which challenges their limits and psychological resources, enabling them to improve themselves (Folkman et al., 1986; Lazarus \& Folkman, 1984). Some stress-triggering situations can be interpreted as challenges and often end up promoting the adaptation or development of cognitive and behavioral faculties, where the individual remains in a good state of mental and physical health, which is an effect of stress known as "eustress" [Faro, 2015; The American Institute of Stress (AIS, 2014)].

In contrast to eustress, the other effect, resulting from maladaptation to stress, is called "distress" (AIS, 2014; Faro, 2015). It is understood that the wearing out of an individual's psychophysiological health has a direct relationship with the chronicity of the effects resulting from stressful events, which is verified in the emergence or deterioration of various pathologies, including hypertension, depression, insomnia, diabetes, and others (Mazon et al., 2008). It is important to highlight that distress not only has an enhancing effect on the state of illness, but also negatively influences the way the person relates in their personal and/or professional circle (Carr, 2014; David \& Quintão, 2012; Morimoto et al., 2019).

Occupational stress among faculty members is specifically associated with various contextual factors, such as time pressure, discipline problems, lack of resources, lack of professional recognition, lack of support, and a diversity of necessary tasks (Boyle et al., 1995). Synthetically, Boyle et al. (1995) categorize teacher stress into five dimensions: workload, student misbehavior, professional recognition, lack of resources, and relationships with colleagues.

Thus, considering the complexity of the stressors in teachers' professional environment, coping strategies are essential. Taking into account that stress is an inexorable occurrence, coping with it is a necessary process and depends, above all, on learning that repeated exposure, at moderate levels, to adversities creates resistance to stress and resilience. The growing evidence from images of the 
human brain endorses the hypothesis that the learning model leads to structural changes in grey and white matter (Nechvatal, 2013).

\begin{abstract}
Most of these studies have focused, however, on relatively simple learning tasks such as juggling or whole-body balancing. It is unclear whether stress coping as a more complex form of learning leads to similar changes in the brain, however opportunities exist from studies of psychotherapeutic interventions for mood and anxiety disorders. Psychotherapies often involve repeated exposure to stressors that challenge current ways of coping and thereby represent a proxy for investigating coping-dependent changes in the brain. (Nechvatal, 2013, p. 2)
\end{abstract}

Some fairly well-known aspects of the work reality of faculty members, such as little participation in the strategic management of the institution, low salaries, classes with lots of students, long timetables, and unavailable, low quality, or insufficient material resources to meet the demand, could be recognized as stressful agents in the work dynamic (Mazon et al., 2008). However, as not all of the circumstances that surround/compose the organizational environment and that give rise to stressors can be controlled, it is up to faculty to discover/seek coping strategies to be able to manage these difficulties and preserve their quality of life, thus maintaining a good organizational environment, satisfaction with their profession, and, finally, equilibrium in their physical and emotional health.

It is important to observe that many studies have sought to measure and analyze the stress level of various professions, using a variety of data collection instruments, such as that of Reis et al. (2005), who also analyzed faculty members in the three states in the South region of Brazil, obtaining an average stress score of the respondents of $49 \%$ on the scale (Cronbach's alpha $=0.86$ ). Soares $(2016)$ also showed an interest in faculty members, identifying in the sample of his study an average stress of $46 \%$ of the score of the instrument used (Cronbach's alpha $=0.893$ ). Soares (2016) also identified, through bibliographical research, that this stress level was higher than the one found in various other professions, such as caregivers of the elderly, bank workers, financial institution employees, military police officers, nursing assistants, geriatric nurses, high-level competitive sailors, community health agents, and elementary and high school teachers. More recently, Liu and Yan (2020) showed an interest in analyzing the stress level of faculty members, where the sample obtained a score of $62.4 \%$ (Cronbach's alpha $=0.897$ ) on the scale of the instrument used.

It is also noted that elementary school teachers form a professional category that is quite widely analyzed by research. In Brazil, Silva et al. (2009) analyzed the activity of these professionals in the state of Pernambuco and identified an average stress level of 55\% on the scale used (Cronbach's alpha $=0.71)$. In Portugal, Caeiro (2010) indicated an average level of 79\% (Cronbach's alpha = 0.965). In England, Jepson and Forrest (2006) detected an average level of $47 \%$ (Cronbach's alpha $=0.76$ ).

Two other studies stand out that detected the stress level of other professions: that of Lorenz et al. (2010) and that of Gershon et al. (2002). The former collected their data on nurses who worked at a Brazilian university hospital, among whom they identified an average level of $66 \%$ on the scale (Cronbach's alpha $=0.687$ to 0.954 ). Gershon et al. (2002), in turn, found an average level of $54 \%$ in research involving police officers in the city of New York, in the United States (Cronbach's alpha $=0.85$ ).

Various other studies, such as that of Griffith et al. (1999), of 780 elementary and high school teachers in England, that of Betoret (2009), which used a sample of 247 high school teachers in Spain, that of Mearns and Cain (2003), also in Spain, that of Chan (1998), of 412 teachers in Hong Kong, that of Parker et al. (2012), of 430 teachers in Australia, and that of Antoniou et al. (2013), of 388 teachers in Greece, are unisonous about how much the teaching environment is filled with stressors and how these adversely affect mental health. From that research, there is evidence that a teacher's routine is surrounded in activities that often force them to experience physical and emotional exhaustion processes, absenteeism, a drop in quality and productivity, increased sick leave, compromised morale, and "psychological detachment," among other occurrences (Garcia \& Benevides-Pereira, 2003).

Finally, it is important to reinforce that beneficial interpersonal relationships, from a mental health viewpoint, cannot do without improving psychological and intellectual competences that tend to be crucial to the individual being able to cope with stressors (Mazon et al., 2008). This is because conflictive contexts require skills such as speed, restraint, and creativity to overcome the obstacles that arise in day-to-day life. These aptitudes can define whether an individual will be able to develop their potentialities without the influence of the avoidable effects of distress or if they will suffer an illness process due to their inaptitude to deal with those same effects.

\subsection{Strategies for Coping with Stress}

People respond to perceptions of threats, damage, and losses in various ways and these responses are called "coping," which is often defined as the effort to prevent or 
reduce a threat, damage, or loss or to reduce the suffering associated with stress (Coleman, 2019; Folkman et al., 1986). In this sense, people can use coping strategies consciously and voluntarily or, conversely, spontaneously and unthinkingly. Naturally, distinguishing between voluntary and involuntary responses to stress is not simple, given that, in truth, responses that begin as intentional and conscious may, with repetition, become automatic (Carver \& Connor-Smith, 2010).

The research on stress, according to Lazarus (2006), should also focus on mapping coping strategies instead to being restricted to mapping stressful events. Stress and coping are intrinsically associated, since a lower or higher level of stress is associated with the effectiveness or ineffectiveness of coping strategies (Lazarus, 2006). Folkman et al. (1986) understand that coping begins with an evaluation regarding the stressor, followed by the choice of coping strategy, and ends with a sort of analysis of its function and utility.

In this sense, Folkman et al. (1986) believe that this entire evaluation process is developed in three stages, as follows: first, the individual will evaluate the stressor, verifying if it causes them some type of discomfort (physical or emotional). At that point, questions such as the following arise: "is there potential damage or benefits regarding the commitments, values, or goals assumed?"; "is a loved one's health or well-being at risk?"; "is there potential damage or benefits to self-esteem?”; as well as others belonging to the evaluation of the level of threat from a stressor to homeostasis (Folkman et al., 1986).

In a secondary evaluation, the individual verifies whether anything can be done to overcome or avoid damage or to improve the prospects of benefits and, as of that moment, seek to combat the stressor (GustemsCarnicer et al., 2019). For that, various coping options are evaluated: altering the situation; accepting it; seeking to obtain more information; or, even, preventing impulsive or counterproductive reactions (Carver et al., 1989). Finally, in the third stage, the previous two converge to determine whether the individual's permanence in that situation is important for their well-being and, if so, whether it is a threat, with the possibility of damage or loss, or a challenge, with the possibility of dominance or benefits (Folkman et al., 1986; Gustems-Carnicer et al., 2019).

Thus, Lazarus and Folkman (1984) define coping as a moderator between a stressor and the effect derived from that stressor processed by means of the mobilization of adaptive cognitive and behavioral resources that seek to overcome, control, withstand, or reduce the demands originating from the social context - demands that, according to the way the individual subjectivizes that experience, exceed or exhaust their resources. The way the individual manages stressful situations is fundamental to understanding the health-illness process (Colossi et al., 2011). It warrants highlighting that coping strategies do not mean the same as defense mechanisms. Coping is the way the individual adapts to stressful demands, while defense is related to the individual's biological adaptation. For that reason, when an individual uses strategies to cope with stress, it produces knowledge and maintains their homeostasis; they can thus eliminate the stressful event or develop the ability to live with it (Folkman et al., 1986; Lazarus \& Folkman, 1984). By escaping from the stressful event, the conditions for learning or managing the situation are not generated, but merely the abandonment of it, remembering that that situation can also generate losses to health, since the individual may feel incompetent, giving rise to depressive states and other symptoms (Colossi et al., 2011).

Thus, the development of coping processes in the organizational environment teachers find themselves part of is important for guaranteeing their quality of life and maintaining their physical and emotional health, enabling them to act competently, even in situations that are far from ideal. Based on this point, Carver et al. (1989) created a classification for coping strategies, later modified by Carver (1997).

Carver et al. (1989) classify coping strategies into three groups: (i) with a focus on the problem - strategies meant to resolve problems or do something to alter the source of stress; (ii) with a focus on emotions - aiming to reduce or manage the emotional suffering associated with or stimulated by a situation; and (iii) the division of the latter into functional or dysfunctional. Coping focused on the problem is directed at the stressor itself: taking measures to remove it, avoid it, or reduce its impact, if it cannot be avoided (Carver \& Connor-Smith, 2010). For example, if dismissals are expected, when an employee uses some coping focused on the problem, they will be able to save money, seek other jobs, obtain better training to increase their prospects of getting hired, or work harder (with more persistence and dedication) in their current job to reduce their probability of being dismissed. Coping focused on emotion, in contrast, aims to minimize the anguish triggered by stressors (Carver \& Connor-Smith, 2010).

According to Carver et al. (1989), there are many ways to reduce stress, and coping focused on emotion includes a wide range of responses, varying from self-control (e.g., relaxing, seeking emotional support) to the expression of negative emotions (e.g., shouting, crying), an attitude of concentrating on negative thoughts (e.g., dwelling over 
things), and an attempt to escape from stressful situations (e.g., evasion, negation of desirable thought).

The effectiveness of the type of coping is analyzed through the result it produces over the stressor, that is, how much it prevented or reduced the threat, damage, or loss or reduced the suffering associated with it (Carver \& ConnorSmith, 2010; Pietrowski et al., 2018). Thus, the inefficiency of coping can be measured by the non-reduction of the existence of suffering or of the perception of stress (distress) (Carver \& Connor-Smith, 2010). This means that some coping strategies can promote a paradoxical increase in intrusive thoughts about the stressor, a more negative mood, and anxiety (Carver \& Connor-Smith, 2010). These authors also indicate that this occurs more easily when the individual associates a positive or negative emotion with certain coping strategies and tends to repeat them, relating them to positive emotion, independently of the possible effectiveness in the new situation.

In this sense, let us analyze, for example, when an individual on a date uses some alcoholic substance to relax and get more comfortable in that situation, and the date results in some type of affective bond. As the affective memory associated with the coping strategy used (alcoholic beverage) for that stressful situation is positive, the person will be able to create an association that will lead them to use the same strategy in another situation which, however, tends not to lead to an efficient result (e.g., a teacher who uses alcohol to deal with students with aggressive behavior).

In light of this, as Carver et al. (1989) clarify, identifying coping strategies is a process of stages, which first consists of a guided process, meaning that it affects what the individual really thinks and does in relation to a specific stressful event, how this emerges, and how it develops. Second, it is a process influenced by the investigation of real situations and of resources to manage it. The emphasis on the context means that individuals, certain variables, and situations together shape the coping efforts. And third, it is a process devoid of preconceptions, as no aprioristic assumptions should be made about what constitutes a good or bad coping strategy.

Moreover, it is important to highlight the three questions underlying the choice of the types of coping identified by Carver et al. (1989): (i) if the individuals have preferred the coping strategies they use, consistently, in a whole series of situations; (ii) if these coping preferences are systematically related with personality variables; and (iii) if coping strategies dispositionally (personality factors, such as their own intelligence or other variables that make the individual responsible for the event) exercise an influence on the specific coping responses.
For Folkman et al. (1986), to analyze coping is to simply sound out a person's efforts to manage demands and how or when that management is successful. Due to this, there are no universal or individual strategies that use only one type that ensures an improvement in someone's perception of stress (Lazarus, 2006). In contrast, by evaluating situational responses to stress, the choices of the type of strategy are framed based on what the individual did or is currently doing in a specific coping episode or during a specific time period, similarly to the way the coping strategy scale is typically administered.

In this sense, for example, Mazon et al. (2008) used a sample of 93 gaucho teachers (from the interior of Rio Grande do Sul) and analyzed, by means of correlation, the associations between types of coping and the dimensions of the Maslach Burnout Inventory (MBI). At the end of the study, they concluded that there was a significant and positive association between the dimensions of emotional exhaustion and depersonalization and the following strategies: coping avoidance; expression of emotions; mental disengagement. In contrast, they negatively associated active coping, emotional support, and positive reinterpretation with the aforementioned dimensions and positively associated them with the professional fulfillment dimension.

Mazon et al. (2008) also highlighted the nonassociation of certain strategies with the dimensions of burnout, and emphasized that some coping strategies employed by teachers when experiencing stress may not reduce their malaise. In fact, some strategies can, besides not causing a feeling of improvement, worsen teachers' state of tension. Also according to Mazon et al. (2008), different effects can derive from the use of various coping modalities. The verification of a particular effect, in the case in particular, will depend not only on the pattern in which the strategies are shaped, but primarily on the way the individual views the stressful event, if it is or is not controllable or recurrent, for example.

The non-association of certain types of coping in the alleviation of stress, that is, the apparent inefficiency of the coping models in the work of Mazon et al. (2008), may reflect a limitation of the technique of the research and of the lack of control of variables to identify the perception of stress. The fact is, however, that some coping strategies can have an enhancing effect on distress due to being misused by the individual (Carver \& Connor-Smith, 2010).

It is common to find evidence that coping strategies can escalate stress or even not promote adaption, as indicated by García et al. (2018), in Chile, Pocinho and Capelo (2009) and Capelo and Pocinho (2016), in Portugal, Salimzadeh et al. (2020), in Canada, and Griffith et al. 
(1999), in England. Moreover, these studies reported that the participants use coping strategies in the following order: strategies focused on the problem, those focused on functional emotions, and those focused on dysfunctional emotions.

These studies confirmed what Carver and ConnorSmith (2010) assert about the possibility of maladaptation when the person uses inappropriate coping strategies for the stressor, that is, without considering the context and the effect that the strategy can cause over the perception of stress; put in other words, ignoring the psychodynamic of the relationship between stress and coping strategies. Thus, when the strategies used manage to reduce unpleasant and demotivating feelings they are considered to be positive/adaptive (Pietrowski et al., 2018). In contrast, when it promotes or contributes symptoms that can hinder the resolution of problems, such as the feeling of guilt, the strategy is considered to be negative/maladaptive (Pietrowski et al., 2018). Therefore, considering the circumstances reported, the following research hypothesis is formulated:

$\mathrm{H}_{1}$ : coping strategies significantly influence the stress self-reported by accounting faculty members.

\section{METHODOLOGY}

The research used a questionnaire sent by email to all the faculty members identified via the institutional websites of the Brazilian HEIs that offered an accounting program according to the Ministry of Education (MEC). The data collection instrument was composed of three blocks: descriptive variables, perception of stress, and frequency of use of coping strategies. Survey registered at the Brazilian Ministry of Health (http://plataformabrasil. saude.gov.br): 52534615.2.0000.5149.

The first block was composed of questions asking about the respondents' sociodemographic profile, as well as aspects related to their work. In the second block, the stress perceived by the faculty was determined using the scale from Boyle et al. (1995), the Teacher Stress Inventory (TSI). This instrument, besides presenting good validity in relation to the research already conducted, has been shown to have a good empirical fit [for example: Griffith et al. (1999); Silva et al. (2009); Boshoff et al. (2018); Liu \& Yan (2020)] given the Cronbach's alpha of higher than 0.8 . For this study, the version developed by Silva et al. (2009) in Portuguese from Portugal was used, having presented internal consistency (Cronbach's alpha $=0.87$ ). With regards to this instrument, it is observed that to bring the questions closer to the Brazilian context, words such as "actividade" were substituted by "atividade."

The TSI is composed of 26 questions for which the participants should attribute a score from 1 to $5(1=$ no stress; 2 = little stress; $3=$ neutral; $4=$ some stress; $5=$ a lot of stress). These questions are distributed in five dimensions proposed by Boyle et al. (1995), according to the relationship with the origin of a teacher's stress: student misbehavior; workload; professional recognition; lack of resources; relationship with colleagues. Based on this, the perceived stress was determined by the sum of the scores attributed by the respondents.

To discover which coping strategies were most used by the faculty to deal with stress and their contribution to controlling stress (third block), the 28-item version of the questionnaire developed by Carver et al. (1989) was used, the Brief COPE Inventory (Coping Orientation to Problems Experienced Inventory). By preferring the version in Portuguese from Portugal (Ribeiro \& Rodrigues, 2004), the questions in the Brief COPE that could present some variation due to regionalism were adapted, such as the expression "a acontecer," substituted by "acontecendo" ("Tento aceitar as coisas tal como estão acontecendo," i.e., "I try to accept things just as they are" in English). As various possible types of coping are concerned, the analyses were conducted according to the 14 dimensions developed by Carver (1997).

The study sample was composed of faculty members who taught in the accounting program in public, private, or non-profit HEIs. To identify the HEIs, the MEC website (https://emec.mec.gov.br) was accessed, seeking those that offered an undergraduate program in accounting, which resulted in the identification of 1,064 HEIs, ignoring the possibility of the same institution having more than one center.

Based on that list, the list of faculty members in the program was sought on the institutional websites. When the institution's website provided the name and email, contact was made via this means. When that information was lacking, contact was made via the program administrator's email, asking for the invitation to participate in the research to be sent to the faculty. After 
this data collection, the emails of 1,955 faculty in Brazil were identified, to whom an invitation to participate in the research was sent. Despite our insistence, in which the invitation was resent six times, the result was 723 replies, of which 563 were considered valid for the analyses conducted in this research. Together with the invitation, the participants were sent a Free and Informed Consent Form (FICF), informing them of the research objective, that their participation would not be compensated, and about the possibility of interrupting their participation at any point in the data collection or after their participation. For this research the onlinepesquisa.com website was used, which provides a platform for elaborating the instrument, sending, and collecting the data.

The data analysis was conducted using a multiple linear regression model, according to model 1 , as well as absolute and relative frequency analyses. After estimating the linear regression, tests were conducted to verify problems related to heteroscedasticity, multicollinearity, and specification error.

$$
E E_{I}=\alpha+\operatorname{EED} X_{1 i}+\beta_{2} X_{2 i}+\beta_{3} X_{3 i}+\cdots+\beta_{k} X_{k i}+e \quad 1
$$

in which $\mathrm{EE} i$ is the stress level perceived by the respondent, $\alpha$ is the constant of the model, EED are the coping strategies by type, $B j(j=1,2, \ldots, k)$ are the coefficients of each explanatory variable, $\mathrm{Xj}(\mathrm{j}=1,2, \ldots, \mathrm{k})$ are the explanatory control variables, $i(\mathrm{i}=1,2, \ldots, \mathrm{k})$ represents each one of the observations of the sample under analysis, and $e$ is the error term of the estimated model.

The limitations of this study are based on two aspects: the sample and collection instrument. With relation to the sample, as the research universe was unknown, the data were collected in a non-randomized way, which does not enable the findings to be extrapolated. With relation to the instrument, it is known that, when using a questionnaire, the respondent may misinterpret the instrument, or they may feel uncomfortable participating in the research, which would result in bias in their answers.

\section{ANALYSIS AND DISCUSSION OF THE DATA}

The application of the questionnaire, carried out exclusively online, resulted in a final sample of 563 valid answers. The data, summarized in Tables 1 and 2, identified that the average age of the respondents was approximately 44 years ( $75 \%$ were aged over 37$)$, most were male (57\%), married or in a stable union (74\%), with at least one child/dependent (69\%), and an average family income of approximately BRL 11,000, among other information about their socioeconomic situation.

Table 1

Quantitative descriptive statistics

\begin{tabular}{|c|c|c|c|c|c|c|}
\hline Variable & Mean & Median & Mode & Minimum & Maximum & $\begin{array}{l}\text { Standard } \\
\text { deviation }\end{array}$ \\
\hline Age & 44.1 & 44.0 & 53.0 & 23.0 & 74.0 & 10.5 \\
\hline Number of dependents & 1.2 & 1.0 & 2.0 & 0.0 & 6.0 & 1.0 \\
\hline Net family income (in BRL thousands) & 11 & 10 & 10 & 1 & 50 & 6.2 thousand \\
\hline Teaching experience (years) & 14.4 & 13.0 & 8.0 & 1.0 & 50.0 & 9.5 \\
\hline Perception of mental health & 4.1 & 4.0 & 4.0 & 1.0 & 5.0 & 0.8 \\
\hline Perception of physical health & 3.9 & 4.0 & 4.0 & 1.0 & 5.0 & 0.8 \\
\hline Weekly number of class hours & 16.1 & 14.0 & 12.0 & 2.0 & 44.0 & 8.6 \\
\hline $\begin{array}{l}\text { Weekly number of hours in another } \\
\text { profession }\end{array}$ & 27.8 & 30.0 & 40.0 & 2.0 & 70.0 & 13.9 \\
\hline
\end{tabular}

Source: Elaborated by the authors. 
Table 2

Qualitative descriptive variables

\begin{tabular}{|c|c|c|c|c|c|}
\hline \multirow[b]{2}{*}{ Variable } & \multicolumn{2}{|c|}{ Frequency } & \multirow[b]{2}{*}{ Variable } & \multicolumn{2}{|c|}{ Frequency } \\
\hline & $\begin{array}{l}\text { Absolute } \\
\text { (n) }\end{array}$ & $\begin{array}{c}\text { Relative } \\
(\%)\end{array}$ & & $\begin{array}{l}\text { Absolute } \\
\text { (n) }\end{array}$ & $\begin{array}{c}\text { Relative } \\
(\%)\end{array}$ \\
\hline Men & 322 & 57 & Affiliation with a private $\mathrm{HEI}$ & 348 & 62 \\
\hline Women & 241 & 43 & Affiliation with a public HEI & 197 & 35 \\
\hline Married/in a stable union & 417 & 74 & Substitute in a public HEI & 18 & 3 \\
\hline Single & 107 & 19 & Administration & 122 & 22 \\
\hline Divorced & 34 & 6 & Accounting & 259 & 46 \\
\hline Widow(er) & 5 & 1 & Law & 14 & 2 \\
\hline Has a dependent & 388 & 69 & Economics & 19 & 3 \\
\hline Has completed a doctorate program & 177 & 31 & Production engineering & 28 & 5 \\
\hline Has completed a master's program & 277 & 49 & Others & 121 & 21 \\
\hline $\begin{array}{l}\text { Has completed a specialization (post- } \\
\text { graduate) program }\end{array}$ & 111 & 20 & $\begin{array}{c}\text { Carries out another professional } \\
\text { activity }\end{array}$ & 311 & 55 \\
\hline Teaches in one period & 292 & 52 & Use of chemical substances & 211 & 37 \\
\hline Teaches in two periods & 213 & 38 & Serious illnesses & 20 & 4 \\
\hline Teaches in three periods & 58 & 10 & Is a manager at the $\mathrm{HEI}$ & 218 & 39 \\
\hline
\end{tabular}

HEI = higher education institution.

Source: Elaborated by the authors.

Regarding the stress level self-reported by the respondents, it was found that the average score reported was 82 points on the scale, that is, $63 \%$ of the upper limit of the TSI (Table 3 ). According to the bibliographical research, this self-reported stress level is only lower than the one found by Lorenz et al. (2010) in a study of nurses at a Brazilian university hospital and the one reported in the work of Caeiro (2010), who collected data on elementary school teachers in Portugal, and very close to the result reported by Liu and Yan (2020).

Table 3

Perceived stress levels by dimension

\begin{tabular}{|c|c|c|c|c|c|c|c|c|}
\hline \multirow[b]{2}{*}{ Dimension } & \multicolumn{3}{|c|}{ Aggregated data from the sample } & \multicolumn{3}{|c|}{ Data per respondent } & \multirow{2}{*}{$\begin{array}{c}\text { Cronbach's } \\
\text { alpha }\end{array}$} & \multirow{2}{*}{$\begin{array}{c}\text { Normality } \\
\text { test }\end{array}$} \\
\hline & Score & $\begin{array}{l}\text { Maximum } \\
\text { score }\end{array}$ & Mean & $\begin{array}{c}\text { Maximum } \\
\text { level }\end{array}$ & Mean level & $\begin{array}{c}\text { Percentage } \\
(\%)\end{array}$ & & \\
\hline Student misbehavior & 12.977 & 19.440 & 2.163 & 30 & 20 & 67 & 0.895 & 0.00 \\
\hline Workload & 12.716 & 19.440 & 2.119 & 30 & 20 & 65 & 0.856 & 0.00 \\
\hline Professional recognition & 10.041 & 16.200 & 2.008 & 25 & 15 & 62 & 0.818 & 0.00 \\
\hline Lack of resources & 9.943 & 16.200 & 1.989 & 25 & 15 & 61 & 0.800 & 0.00 \\
\hline Relationship with colleagues & 7.550 & 12.960 & 1.888 & 20 & 12 & 58 & 0.828 & 0.00 \\
\hline General stress level & 53.227 & 84.240 & - & 130 & 82 & 63 & 0.945 & 0.00 \\
\hline
\end{tabular}

Source: Elaborated by the authors.

All these indicators show that stress for teachers is clearly a multifaceted event, as described by Boyle et al. (1995). Therefore, it is established that stress in the university environment takes a complex form, which is, alas, expected, given the characteristics of the career of faculty members, who have to carry out multiple activities related to teaching, research, and outreach, as well as HEI bureaucracy/management. Moreover, a significant part of the sample (55\%) carries out another professional activity and this complex context can mean the professional is subject to hardships while acting in another work environment.

With relation to the data collected with the Brief COPE, it can be seen that only two dimensions had a Cronbach's alpha lower than 0.7 (Table 4). It is also found that only three dimensions (denial, behavioral divestment, and substance use) are used little by the respondents. Of the dimensions of the strategies focused on the problem, "acceptance" and "use of social and emotional support" are not among the first, while "self-reproach" (dysfunctional 
emotion) and religion (functional emotion) are more recurrent for the sample. Persisting in the analysis of the prevalence of the dimensions of the coping strategies, those focused on the problem present a higher prevalence $(76 \%$ on the scale) in relation to the rest, however those focused on functional emotions are used more frequently (62\%) by the faculty members. Finally, those strategies focused on dysfunctional emotions have a lower incidence (47\%).

Table 4

Scores of the coping strategies by dimension

\begin{tabular}{|c|c|c|c|c|c|c|c|c|}
\hline \multirow[b]{2}{*}{ Dimension } & \multicolumn{3}{|c|}{ Aggregated data from the sample } & \multicolumn{3}{|c|}{ Mean data per respondent } & \multirow{2}{*}{$\begin{array}{l}\text { Cronbach's } \\
\text { alpha }\end{array}$} & \multirow{2}{*}{$\begin{array}{c}\text { Normality } \\
\text { test }\end{array}$} \\
\hline & Score & $\begin{array}{l}\text { Maximum } \\
\text { score }\end{array}$ & Mean & $\begin{array}{l}\text { Maximum } \\
\text { level }\end{array}$ & Mean level & $\begin{array}{l}\text { Percentage } \\
(\%)\end{array}$ & & \\
\hline Planning & 4.059 & 4.760 & 2.030 & 8 & 6.8 & 85 & 0.766 & 0.04 \\
\hline Active coping & 3.918 & 4.760 & 1.959 & 8 & 6.6 & 82 & 0.780 & 0.71 \\
\hline Positive reinterpretation & 3.769 & 4.760 & 1.885 & 8 & 6.3 & 79 & 0.863 & 0.55 \\
\hline Using instrumental support & 3.476 & 4.760 & 1.738 & 8 & 5.9 & 73 & 0.914 & 0.76 \\
\hline Self-reproach & 3.354 & 4.760 & 1.677 & 8 & 5.6 & 71 & 0.552 & 0.53 \\
\hline Religion & 3.332 & 4.760 & 1.666 & 8 & 5.6 & 7 & 0.884 & 0.00 \\
\hline Acceptance & 3.258 & 4.760 & 1.629 & 8 & 5.5 & 69 & 0.689 & 0.97 \\
\hline $\begin{array}{l}\text { Using social and emotional } \\
\text { support }\end{array}$ & 3.227 & 4.760 & 1.614 & 8 & 5.4 & 68 & 0.919 & 0.71 \\
\hline Expression of feelings & 2.992 & 4.760 & 1.496 & 8 & 5.0 & 63 & 0.933 & 0.02 \\
\hline Humor & 2.726 & 4.760 & 1.363 & 8 & 4.6 & 57 & 0.821 & 0.28 \\
\hline Self-distraction & 2.631 & 4.760 & 1.316 & 8 & 4.4 & 55 & 0.720 & 0.99 \\
\hline Denial & 2.304 & 4.760 & 1.152 & 8 & 3.9 & 48 & 0.803 & 0.23 \\
\hline Behavioral divestment & 1.737 & 4.760 & 869 & 8 & 2.9 & 37 & 0.859 & 0.00 \\
\hline $\begin{array}{l}\text { Substance use (medication/ } \\
\text { alcohol) }\end{array}$ & 1.505 & 4.760 & 753 & 8 & 2.5 & 32 & 0.928 & 0.00 \\
\hline
\end{tabular}

Source: Elaborated by the authors.

It is found from the analysis of the coping strategies used, as is reported by Capelo and Pocinho (2016), García et al. (2018), Pocinho and Capelo (2009), and Salimzadeh et al. (2020), that faculty members have a preference for strategies focused on the problem, followed by those focused on functional emotions and, finally, those focused on dysfunctional emotions. This is positive, considering that using strategies focused on problems means more adaptive actions, which can result in better moderation of stress.

To understand a little more about the association between stress and coping strategies, the components of the sample were classified into two groups: those that presented stress levels up to the mean (value equal to or lower than 82), considered less vulnerable to the academic stressors presented in the TSI, and those that were above the mean (value higher than or equal to 83 ), resulting in one group of 266 respondents (more vulnerable to stress) and another with 297 (less vulnerable), as presented in Table 5. This procedure revealed that, in relation to the strategies focused on the problem, there is no statistically significant difference between the two groups. However, in relation to the strategies focused on functional and dysfunctional emotions, the faculty who are most vulnerable to stress make more intensive use of these $(\mathrm{p}<0.05)$.

Table 5

Association between vulnerability to stress and coping strategies

\begin{tabular}{|c|c|c|c|c|c|c|c|c|c|c|c|c|}
\hline \multirow[b]{2}{*}{ Variable } & \multicolumn{5}{|c|}{ Most vulnerable } & \multicolumn{5}{|c|}{ Least vulnerable } & \multicolumn{2}{|c|}{ p-value } \\
\hline & $\mathbf{n}$ & Mean & Median & Mode & $\begin{array}{l}\text { Standard } \\
\text { deviation }\end{array}$ & $\mathbf{n}$ & Mean & Median & Mode & $\begin{array}{l}\text { Standard } \\
\text { deviation }\end{array}$ & $t$ test & $F$ test \\
\hline Stress & 266 & 91 & 93 & 89 & 18 & 297 & 63 & 66 & 49 & 14 & 0.0000 & 0.0000 \\
\hline Problem & 266 & 37 & 37 & 36 & 6 & 297 & 36 & 36 & 41 & 5 & 0.8181 & 0.6368 \\
\hline Dysfunctional & 266 & 15 & 14 & 14 & 3 & 297 & 14 & 13 & 13 & 4 & 0.0029 & 0.0041 \\
\hline Functional & 266 & 20 & 20 & 20 & 4 & 297 & 19 & 18 & 18 & 4 & 0.0186 & 0.0091 \\
\hline
\end{tabular}

Source: Elaborated by the authors. 
Finally, to determine the effect of the coping strategies on modulating the stress perceived by the faculty members, as informed in the methodology, the regression presented in Table 6 was estimated. After estimating the data, the test was conducted to determine any restrictions in relation to heteroscedasticity (White test), multicollinearity (variance inflation factor [VIF]), and specification error (Ramsey regression equation specification error test [RESET]). According to the result of the tests, the model did not present any heteroscedasticity problem $(\mathrm{p}=0.4943)$. Thus, the model analyzed was the one presented in Table 6, estimated using the Stepwise method, considering 10\% significance. Given this, the multicollinearity problem was analyzed, presenting mean values of 1.25 , the highest being 1.46 for the denial variable $(1 / \mathrm{VIF}=0.684552)$. Finally, the specification error test indicated that the model (according to the Stepwise method) did not present this problem (0.4599). Thus, considering the final model, the significance result of the model was below $1 \%$ (F prob = 0.0000 ) and the adjusted $\mathrm{R}^{2}$ was 0.1773 .

\section{Table 6}

Stepwise model

\begin{tabular}{|c|c|c|c|}
\hline \multirow{2}{*}{ Active coping } & $-2.1453^{* *}$ & \multirow{2}{*}{ Married } & $8.6927^{* * *}$ \\
\hline & $(0.9514)$ & & $(3.1549)$ \\
\hline \multirow{2}{*}{ Self-reproach } & $1.6598^{* * *}$ & \multirow{2}{*}{ Divorced } & $17.9350^{* * *}$ \\
\hline & $(0.8567)$ & & $(6.1374)$ \\
\hline \multirow{2}{*}{ Denial } & $1.7704^{* *}$ & \multirow{2}{*}{ Having a dependent } & $1.6598^{* * *}$ \\
\hline & $(0.7912)$ & & $(0.85675)$ \\
\hline \multirow{2}{*}{ Behavioral divestment } & $-2.3402 * * *$ & \multirow{2}{*}{ Family income } & $-0.0003 *$ \\
\hline & $(0.8173)$ & & $(0.0002)$ \\
\hline \multirow{2}{*}{ Age } & $-0.3250^{* * *}$ & \multirow{2}{*}{ Public HEl } & $5.7825^{* *}$ \\
\hline & $(0.1128)$ & & $(2.5210)$ \\
\hline \multirow{2}{*}{ Gender } & $4.5538^{* * *}$ & \multirow{2}{*}{ Perception regarding mental state } & $-5.3273^{* * *}$ \\
\hline & $(2.3271)$ & & $(1.4151)$ \\
\hline \multirow{2}{*}{ Constant } & $113.9179^{* * *}$ & & \\
\hline & $(10.1228)$ & & \\
\hline
\end{tabular}

HEI = higher education institution .

***, ${ }^{* *},{ }^{*}=p<0.01, p<0.05$, and $p<0.1$, respectively.

Source: Prepared by the authors.

Based, therefore, on the results of this study, despite the extensive number of coping strategies available to teachers (14, according to the Brief COPE), only four were shown to be statistically significant for modulating the effect of stress $(\mathrm{p}<0,1)$, which confirms $\mathrm{H}_{1}$. This result is aligned with the results of Capelo and Pocinho (2016), García et al. (2018), Griffith et al. (1999), Pocinho and Capelo (2009), and Salimzadeh et al. (2020), who also identified a limited number of equally significant strategies for modulating stress and even some that when employed did not promote any adaptation.

It was observed that two coping strategies presented a negative effect over stress (active coping and behavioral divestment), the result being that when faculty employ them, their suffering with the stressor can be maintained at acceptable levels for them or even eliminated, thus enabling adaptation. However, a warning should be given: while active coping is among the strategies focused on resolving the problem, behavioral divestment is among the strategies focused on dysfunctional emotions.
The greater the use of coping strategies with a focus on controlling the problem, the more measures the faculty seeks to remove it, avoid it, or reduce its impact, if it cannot be avoided (Carver \& Connor-Smith, 2010). This means that the faculty reflect on the situations generating stress in their job and adopt adaptive coping measures, resulting in a greater probability of being able to make decisions enabling them to address or withstand the stressors and achieve their goals (Pietrowsk et al., 2018). That is, the individual may seek out the HEI's management, dedicate more time and energy to the job, try to be more effective, learn new knowledge, change didactic strategies, seek to change policies, and other strategies capable of modifying the situation that does not seem favorable to them.

With relation to behavioral divestment, despite, in the context analyzed, it enabling the perception of stress to be alleviated, the use of this type of strategy can result in disengagement (Carver et al., 1989). Imagining a situation in which the teacher resolves to make use of an active learning strategy that they had not used before in class, 
some adversities would appear which will result in tension. If instead of seeking to improve their skill (they could speak with more experienced colleagues, for example) the teacher ceases to use this new pedagogical strategy, they will not experience that situation. Yet, this will not enable them to develop their skill and competence in a new didactic approach, which could even contribute to and increase the students' learning.

Regarding the two strategies, self-reproach and denial, which are significant and increase stress, it is seen that these involve a result that, despite being expected (Carver \& Connor-Smith, 2010; Griffith et al., 1999; Salimzadeh et al., 2020), reinforces the need for faculty to be better armed with adaptive strategies. This is because, by having thoughts that reduce or even deny the importance of the work, the faculty blame themselves for all of the unpleasant situations or difficulties they encounter in the academic environment. This strategy ends up consuming a lot of mental energy, resulting in emotional exhaustion (Pocinho \& Capelo, 2009).

It is reinforced that the apparent inefficiency of a large number of coping strategies (Table 6) may be related with two more evident causes. The first, in relation to the Brief COPE, may be poor measurement. This explanation for the results, however, appears not to prevail when it is observed that the instrument had a general Cronbach's alpha $=0.859$. However, the Brief COPE is still little used in Brazil, despite being widely used internationally and there being an initiative to validate this instrument in the Brazilian context (Gonçalves-Câmara et al., 2019).

The second piece of evidence regarding the results is that faculty may be practicing what Carver and Connor-Smith (2010) reported as positive reinforcement obtained through successfully using a coping strategy in another situation and that the individual insists on using, despite its inefficiency, in a new context. Considering the results obtained, this possibility appears to be more credible, since various strategies obtained a negative association in relation to the stress reported by the participants. According to this logic, it is believed that the low effectiveness of the coping strategies employed by the faculty is associated with the evidence that most of them would be in a state of eustress, that is, despite perceiving high stress levels, the faculty maintain their homeostasis.

In relation to the control variables, estimated using the Stepwise method, eight were considered significant $(\mathrm{p}<0.1)$ and only three indicated reducing perceived stress, therefore, the other five signaled that they increased this perception. Thus, the fact of being a woman, being married or divorced, having dependents, and being from a public HEI are conditions that increased the self-reported stress. In contrast, age (getting older), family income, and perception about their own mental health are variables that were shown to be capable of mitigating the faculty members' stress.

There are big individual differences in cognitive and physiological responses to stress, and the relationship between stress and health is influenced by a range of moderating variables, including personality, context, experiences, and biological aspects, among others (AIS, 2014; Faro, 2015; Lazarus \& Folkman, 1984). That is, when evaluating perceived stress and the way it affects people's quality of life, these variables should be considered. Therefore, this research signals that the 12 variables presented in Table 6 are statistically significant $(\mathrm{p}<0.1)$ for the sample.

The first factor to be discussed is age. Folkman et al. (1986) sustains that individuals become more mature in their coping behaviors throughout the aging process, that is, they may show an increase in allocentric (in contrast with egocentric) thinking and in their use of wisdom, detachment, and humor. This is confirmed in the present study, by demonstrating that the older the faculty who participated in the research was, the lower their perception of stress.

Also according to the study of Folkman et al. (1986), besides changes in the way of subjectivizing experiences and modifying the coping strategies preferred by individuals, as they age, over time, even the most significant stressors alter. Younger people usually perceive the stressors associated with finance, work, maintaining the home, personal life, family, and friends more intensely than older ones (Folkman et al., 1986). As they age, there is a greater emphasis on questions related to the environment, social life, and their own health. That is, people's attentional focus migrates and work ceases to be their greatest concern during the aging process. This change in focus appears to be coherent when considering that an older person's life circumstances are different from a younger one's circumstances, especially because aging demands greater attention to be paid to one's own physiological state.

Another situation that became evident in the present study relates to the stress perceived by female respondents, which is greater than that perceived by male ones. In this sense, two aspects need to be considered to explain this result: the psychosocial context and the physiological context of the respondents.

Despite the molecular origins of this sexual dimorphism in relation to stress still being quite obscure (Brivio et al., 2020), a physiological approach in relation to the way hormones act, especially estrogen, progesterone, and testosterone, may explain the difference in how men and 
women are affected by stress (Hyde \& Mezulis, 2020). Thus, there is evidence (Brivio et al., 2020) that many genes related to stress are regulated in a specific way by each group. Moreover, transcriptomic studies have shown that the physiological pathways and networks in individuals of the male and female genders are not equally affected by exposure to stress, even involving different levels of processing and, thus, its modulation (Brivio et al., 2020).

Along these same lines, the psychosocial context of women differentiates them from men, as the social roles also appear to be more relevant in the life experiences and the meaning attributed to stress for women than for men (Matud, 2004). The place that the woman has to occupy to correspond to that stereotypical social expectation determines the range of experiences with the potential for mental suffering, which increases the chance of exposure to some stress factors and impedes the presence of other spaces with fewer stressors that are therefore more mentally favorable to their mental health. As Matud (2004) clarifies, the conditions that people face when they occupy a particular role is a source of differential stress or of mitigation, as they may have very different experiences in the same function, considering the subjectivation that each one makes of their experiences and taking into account the range of previous learning and, of course, the social stereotypes built.

It is also considered that the position of the woman at work and in the family is less favorable, as she carries a heavier load of demands and limitations, built based on the values that the collective that composes her surroundings considers in the formation of the feminine and masculine roles for society. The research also identified differences in relation to income (women stated they had a family income a thousand BRL lower; $\mathrm{p}<0.05$ ), as well as the female faculty indicating a worse perception of their health than the male ones $(p<0.01)$. These results show that the social context of women is more complex when compared with that of men. Therefore, women and men differ in the frequency of their occupation of social roles and in their subjectivations, even in similar social roles, which can lead female teachers to the condition of chronic stress.

Surprisingly, the data revealed that the social context of the respondents is capable of escalating the stress perceived by the faculty members in the sample. This conclusion was observed based on the variables associated with marital status and the variables regarding children and dependents. There was an expectation that family social support could contribute to alleviating the teachers' stress, as the family context could be a source of emotional gratification/satisfaction, which would be capable of reducing the stress perceived (Coombs, 1991; Gmelch et al., 1986). It was signaled, however, that the respondents perceived the relationship with their family members as a source of stress, whether because they were married or divorced, or because they had children or dependents (elderly parents, for example).

Families are involved in relatively stable patterns of interaction while they try to balance the demands they face, from the members, from the family unit, or from the community context, with their abilities to achieve a level of family adjustment (Patterson, 2002). There are moments, however, in which family demands significantly exceed their adaptive capacity, especially considering the contemporary social context, which gives the heads of the family, particularly the women, high work demands, making time scarce for dedication to the family, reducing the possibilities of adjustment (Afifi et al., 2020). When this imbalance persists, families experience a crisis, a period of significant imbalance, and disharmony. Often, the crisis is a point of inflexion for the family, causing a major change in its structure and in the patterns of interaction, causing a situation of vulnerability of the family members to the stressor (Patterson, 2002).

With relation to income, the results indicated that the higher the income, the lower the perception of stress. Santiago et al. (2011) put forward that a person's socioeconomic situation is capable of influencing their psychological health, considering that, according to the authors, there is evidence that the lower an individual's socioeconomic condition is, the more situational stressors they experience in their daily life. This occurs because income provides easier access to medical treatments, leisure, consumer goods, food, and other resources. Thus, the lower the income is, the more stressors there will be in the context, leaving the individual more vulnerable to these, overloading their mental and physical resources, and resulting in a greater perception of stress (Santiago et al., 2011).

In light of the result regarding the faculty affiliated with a public HEI, it was found that this fact - being a faculty member at this type of institution - increased the respondents' perception of stress. This discovery is possibly related to the context of an HEI's professional activity, considering that this type of institution requires more dedication (in the case of the sample, $65 \%$ of the respondents from the public HEIs work full-time in teaching activities, while among the other affiliations, this proportion is $35 \%$ ). This situation requires more effort from the individuals in their various activities, especially in research activities, since continuous research productivity has become a core expectation of teaching staff (Jacobs \& Winslow, 2004). 
There is more conflict or ambiguity about what fulltime teachers are expected to do, where there may be a greater need to spend nights or weekends doing research if they are interested in seeking a stable position or guaranteeing such a position, contributing to an even lesser separation between their professional and personal lives (Catano et al., 2010). Finally, through being more involved with the HEI (which increases their emotional investment and expectations), the respondents affiliated as full-time employees more strongly perceived stressors, making them more vulnerable to stress.

The last variable analyzed relates to self-perception of mental health, which indicated that the higher this is, the lower the perception of stress will be. This means that maintaining a healthy and positive state of mental health enables sensitivity to stressors to be lower, suggesting the importance of taking care of it.

The more the individual is able to maintain their mental health during episodes of stress, the more they will be able to manage this situation and shape their perception of stress, as a positive state of mental health is an important facilitator of adaptive coping and adjustment to acute and chronic stress, and it may underlie the beneficial effects of interventions, such as relaxation therapies (Folkman \& Moskowitz, 2000). Put in another way, taking care of one's state of mental health may serve as support, helping to motivate and overcome suffering, by providing breathers that would give a momentary respite from anguish, and "restorers" that would replenish coping resources (Folkman, 2008).

\section{CONCLUSION}

The experience an individual undergoes, whenever they are heavily pressured to deal with some obstacle, impediment, or imminent threat, is stressful and, depending on the frequency and persistence of that situation, they may depart from a situation of homeostasis and succumb to distress (Carver \& Connor-Smith, 2010; França \& Rodrigues, 2011; Ganzel et al., 2010; Lazarus \& Folkman, 1984). For that reason, coping strategies are fundamental for maintaining personal biopsychophysiological well-being.

This study revealed that, of the 14 categories of strategies summarized by Carver et al. (1989), only four (active coping, self-reproach, denial, and behavioral divestment) have a statistically significant effect $(\mathrm{p}<0.05)$ over the stress reported by faculty members. However, it was found that two (self-reproach and denial) increase that perceived stress. Part of that question is explained by the fact that they are coping strategies focused on dysfunctional emotions, therefore they may not fulfill their role as mitigators of distress (Carver \& ConnorSmith, 2010). So, seeking to deny the stressful events or, frequently, blaming oneself for them in the context analyzed, besides being revealed to be ineffective in dealing with the teachers' stress, was revealed to be a way of increasing it.

In contrast, using attitudes to modify or trying to seek mechanisms to assimilate the situation that causes suffering, that is, endeavoring to remove, attenuate, or improve the stressful event, tends to make people more adaptive. Similarly, the possibility of disengaging from situations that could be a cause of suffering for the faculty was indicated as being a favorable alternative for maintaining their well-being.
Thus, considering the importance of work, whether for faculty members' socioeconomic situation or for their well-being, the difficulties caused by stress are painful and, for that reason, it is vital to take action to mitigate it, including because there is no doubt that the quality of higher education significantly depends on the presence of high-level teaching staff.

In this sense, faculty members could invest efforts in learning to use coping strategies that better promote adaptation to the stressors they encounter. The results indicated that various strategies do not promote adaptation, enabling it to be said that the mental effort invested in their application needs to be well directed, which can be done by means of training, psychological support, dialogue with colleagues, self-awareness practices, and other forms of acquiring more skill in managing academic stressors.

In contrast, it is up to the institution to provide guidance to faculty members (via workshops, courses, lectures, and other spaces for debate) with respect to time management and managing their work processes, providing them with elements to manage their workload. Moreover, the manager also undoubtedly plays an important role in the attribution of demands. Thus, besides it being essential to take into account the professional's skills and competences, the workload distribution, even when the teaching staff is reduced (due, for example, to leave, dismissals, and resignations), needs to be as equal as possible. In this arduous task, it is essential for the program administrator to open up a dialogue. A discussion among the actual actors involved, through being called upon to take part in the debate and to influence the final decision, tends to generate a positive effect over feelings of control and by 
indicating that the program administrator cares about the professional, their needs, and limitations (participative management), thus also revealing itself to be an effective support mechanism.

\section{REFERENCES}

Afifi, T. D., Harrison, K., Zamanzadeh, N., \& Acevedo Callejas, M. (2020). Testing the theory of resilience and relational load in dual career families: Relationship maintenance as stress management. Journal of Applied Communication Research, 48(1), 5-25. https://doi.org/10.1080/00909882.2019.1706097

Antoniou, A. S., Ploumpi, A., \& Ntalla, M. (2013). Occupational stress and professional burnout in teachers of primary and secondary education: The role of coping strategies. Psychology, 4(3), 349. http://dx.doi.org/10.4236/psych.2013.43A051

Araújo, T. S., Miranda, G. J., \& Pereira, J. M. (2017). Satisfação dos professores de contabilidade no Brasil. Revista Contabilidade \& Finanças, 28(74), 264-281. https://doi.org/10.1590/1808$057 \times 201703420$

Betoret, F. D. (2009). Self-efficacy, school resources, job stressors and burnout among Spanish primary and secondary school teachers: A structural equation approach. Educational Psychology, 29(1), 45-68. https://doi. org/10.1080/01443410802459234

Boshoff, S. M., Potgieter, J. C., Ellis, S. M., Mentz, K., \& Malan, L. (2018). Validation of the Teacher Stress Inventory (TSI) in a multicultural context: The SABPA study. South African Journal of Education, 38(Suppl 2), S1-S13. https://doi. org/10.15700/saje.v38ns2a1491

Boyle, G. J., Borg, M. G., Falzon, J. M., \& Baglioni, A. J., Jr. (1995). A structural model of the dimensions of teacher stress. British Journal of Educational Psychology, 65(1), 49-67. https://doi. org/10.1111/j.2044-8279.1995.tb01130.x

Brivio, E., Lopez, J. P., \& Chen, A. (2020). Sex differences: Transcriptional signatures of stress exposure in male and female brains. Genes, Brain and Behavior, 19(3), e12643. https://doi.org/10.1111/gbb.12643

Caeiro, R. M. D. N. (2010). Stress ocupacional e avaliação de desempenho nos professores: contributos para uma psicodinâmica do trabalho [Master's Dissertation]. Centro Universitário de João Pessoa.

Capelo, R., \& Pocinho, M. (2016). Estratégias de coping: contributos para a diminuição do stresse docente. Psicologia, Saúde e Doenças, 17(2), 282-294. http://dx.doi. org/10.15309/16psd 170213

Carr, A. R. (2014). Stress levels in tenure-track and recently tenured faculty members in selected institutions of higher education in Northeast Tennessee [Doctoral Thesis]. East Tennessee State University. https://dc.etsu.edu/etd/2329

Carver, C. S. (1997). You want to measure coping but your protocol' too long: Consider the brief cope. International Journal of Behavioral Medicine, 4(1), 92-100. https://doi. org/10.1207/s15327558ijbm0401_6

Carver, C. S., \& Connor-Smith, J. (2010). Personality and coping. Annual Review of Psychology, 61, 679-704. https://doi. org/10.1146/annurev.psych.093008.100352
Carver, C. S., Scheier, M. F., \& Weintraub, J. K. (1989). Assessing coping strategies: a theoretically based approach. Journal of Personality and Social Psychology, 56(2), 267. https://psycnet. apa.org/doi/10.1037/0022-3514.56.2.267

Catano, V., Francis, L., Haines, T., Kirpalani, H., Shannon, H., Stringer, B., \& Lozanzki, L. (2010). Occupational stress in Canadian universities: A national survey. International Journal of Stress Management, 17(3), 232. https://psycnet.apa. org/doi/10.1037/a0018582

Chan, D. W. (1998). Stress, coping strategies, and psychological distress among secondary school teachers in Hong Kong. American Educational Research Journal, 35(1), 145-163.

Clunies-Ross, P., Little, E., \& Kienhuis, M. (2008). Self-reported and actual use of proactive and reactive classroom management strategies and their relationship with teacher stress and student behaviour. Educational Psychology, 28(6), 693-710. https://doi.org/10.1080/01443410802206700

Coleman, J. (2019). Exploring relationships between parenting style, perceived stress, coping efficacy and coping strategies in foster parents [Doctoral Thesis]. Philadelphia College of Osteopathic Medicine. https://digitalcommons.pcom.edu/psychology_ dissertations/512/

Colossi, E. G., Calesso Moreira, M., \& Pizzinato, A. (2011). Estratégias de enfrentamento utilizadas pela equipe de enfermagem de um CTI adulto perante situações de estresse. Ciência \& Saúde, 4(1), 14-21. https://doi. org/10.15448/1983-652X.2011.1.7167

Coombs, R. H. (1991). Marital status and personal well-being: A literature review. Family Relations, 40(1), 97-102. https://doi. org/10.2307/585665

David, I. C., \& Quintão, S. (2012). Burnout in teachers: Its relationship with personality, coping strategies and life satisfaction. Acta Médica Portuguesa, 25(3), 145-155.

Embse, N., Ryan, S. V., Gibbs, T., \& Mankin, A. (2019). Teacher stress interventions: A systematic review. Psychology in the Schools, 56(8), 1328-1343. https://doi.org/10.1002/ pits. 22279

Faro, A. (2015). Estresse e distresse: estudo com a Escala de Faces. Temas em Psicologia, 23(2), 341-354.

Faro, A., \& Pereira, M. E. (2013). Estresse: revisão narrativa da evolução conceitual, perspectivas teóricas e metodológicas. Psicologia, Saúde \& Doenças, 4(1), 78-100.

Ferenc, A. V. F., \& Saraiva, A. C. L. C. (2010). Os professores universitários, sua formação pedagógica e suas necessidades formativas. In Convergências e tensões no campo da formação e do trabalho docente (pp. 573-589). Autêntica.

Folkman, S. (2008) The case for positive emotions in the stress process. Anxiety, Stress, \& Coping: An International Journal, 21(1), 3-14. https://doi.org/10.1080/10615800701740457 
Folkman, S., \& Moskowitz, J. T. (2000). Stress, positive emotion, and coping. Current Directions in Psychological Science, 9(4), 115-118. https://doi.org/10.1111\%2F1467-8721.00073

Folkman, S., Lazarus, R. S., Dunkel-Schetter, C., DeLongis, A. \& Gruen, R. J. (1986). Dynamics of a stressful encounter: Cognitive appraisal, coping, and encounter outcomes. Journal of Personality and Social Psychology, 50(5), 992-1003. https:// psycnet.apa.org/doi/10.1037/0022-3514.50.5.992

França, A. C. L., \& Rodrigues, A. L. (2011). Stress e trabalho: uma abordagem psicossomática. ( ${ }^{\text {th }}$ ed.). São Paulo: Atlas.

Ganzel, B. L., Morris, P. A., \& Wethington, E. (2010). Allostasis and the human brain: Integrating models of stress from the social and life sciences. Psychological Review, 117(1), 134. http://dx.doi.org/10.1037/a0017773

García, F. E., Barraza-Peña, C. G., Wlodarczyk, A., AlvearCarrasco, M., \& Reyes-Reyes, A. (2018). Psychometric properties of the Brief-COPE for the evaluation of coping strategies in the Chilean population. Psicologia: Reflexão e Crítica, 31, 22. https://dx.doi.org/10.1186/s41155-018-0102-3

Garcia, L. P., \& Benevides-Pereira, A. M. T. (2003). Investigando o burnout em professores universitários. Revista Eletrônica InterAção Psy, 1(1), 76-89.

Gershon, R. R., Lin, S., \& Li, X. (2002). Work stress in aging police officers. Journal of Occupational and Environmental Medicine, 44(2), 160-167. https://doi.org/10.1097/00043764-200202000 00011

Gmelch, W. H., Wilke, P. K., \& Lovrich, N. P. (1986). Dimensions of stress among university faculty: Factor-analytic results from a national study. Research in Higher Education, 24(3), 266-286. https://doi.org/10.1007/BF00992075

Gonçalves-Câmara, S., Carlotto, M. S., \& Bedin, L. M. (2019). Evidências de validade da versão reduzida do Coping Orientation to Problems Experienced Inventory (COPE) com trabalhadores brasileiros. Psicogente, 22(41), 33-50. http:// dx.doi.org/10.17081/psico.22.41.3301

Griffith, J., Steptoe, A., \& Cropley, M. (1999). An investigation of coping strategies associated with job stress in teachers. British Journal of Educational Psychology, 69(4), 517-531. https://doi. org/10.1348/000709999157879

Gustems-Carnicer, J., Calderon, C., Batalla-Flores, A., \& Esteban-Bara, F. (2019). Role of coping responses in the relationship between perceived stress and psychological well-being in a sample of Spanish educational teacher students. Psychological Reports, 122(2), 380-397. https://doi. org/10.1177\%2F0033294118758904

Hyde, J. S., \& Mezulis, A. H. (2020). Gender differences in depression: Biological, affective, cognitive, and sociocultural factors. Harvard Review of Psychiatry, 28(1), 4-13. https://doi. org/10.1097/HRP.0000000000000230

Jacobs, J. A., \& Winslow, S. E. (2004). Overworked faculty: Job stresses and family demands. The ANNALS of the American Academy of Political and Social Science, 596(1), 104-129. https://doi.org/10.1177\%2F0002716204268185

Jepson, E., \& Forrest, S. (2006). Individual contributory factors in teacher stress: The role of achievement striving and occupational commitment. British Journal of Educational Psychology, 76(1), 183-197. https://doi. org/10.1348/000709905X37299

Lazarus, R. S. (2006). Stress and emotion: A new synthesis. Springer Publishing Company.

Lazarus, R. S., \& Folkman, S. (1984). Stress, appraisal and coping. Springer Publishing Company.

Liu, M., \& Yan, Y. (2020). Anxiety and stress in in-service Chinese university teachers of arts. International Journal of Higher Education, 9(1), 237-248.

Lorenz, V. R., Benatti, M. C. C., \& Sabino, M. O. (2010). Burnout and stress among nurses in a university tertiary hospital. Revista Latino-Americana de Enfermagem, 18, 1084-1091. https://doi.org/10.1590/S010411692010000600007

Machado, P. G. B., Porto-Martins, P. C., \& Amorim, C. (2012). Engagement no trabalho entre profissionais da educação. Revista Intersaberes, 7(13), 193-214. https://doi.org/10.22169/ intersaberes.v7i13.257

Matud, M. P. (2004). Gender differences in stress and coping styles. Personality and Individual Differences, 37(7), 14011415. https://doi.org/10.1016/j.paid.2004.01.010

Mazon, V., Carlotto, M. S., \& Câmara, S. (2008). Síndrome de burnout e estratégias de enfrentamento em professores. Arquivos Brasileiros de Psicologia, 60(1), 55-66.

Mearns, J., \& Cain, J. E. (2003). Relationships between teachers' occupational stress and their burnout and distress: Roles of coping and negative mood regulation expectancies. Anxiety, Stress \& Coping, 16(1), 71-82. https://doi.org/10.1080/106158 0021000057040

Morimoto, H., Furuta, N., Kono, M., \& Kabeya, M. (2019). Stress-buffering effect of coping strategies on interrole conflict among family caregivers of people with dementia. Clinical Gerontologist, 42(1), 34-46. https://doi.org/10.1080/07317115 .2017 .1368764

Nechvatal, J. M. (2013). Stress coping changes the brain [Doctoral Thesis]. Stanford University.

Parker, P. D., Martin, A. J., Colmar, S., \& Liem, G. A. (2012). Teachers' workplace well-being: Exploring a process model of goal orientation, coping behavior, engagement, and burnout. Teaching and Teacher Education, 28(4), 503-513. https://doi. org/10.1016/j.tate.2012.01.001

Patterson, J. M. (2002). Integrating family resilience and family stress theory. Journal of Marriage and Family, 64(2), 349-360. https://doi.org/10.1111/j.1741-3737.2002.00349.x

Pietrowski, D. L., de Oliveira Cardoso, N., \& do Nascimento Bernardi, C. C. (2018). Estratégias de coping frente à síndrome de burnout entre os professores: uma revisão integrativa da literatura nacional. Contextos Clínicos, 11(3), 397-409. https://doi.org/10.4013/ctc.2018.113.10

Pocinho, M., \& Capelo, M. R. (2009). Vulnerabilidade ao stress, estratégias de coping e autoeficácia em professores portugueses. Educação e Pesquisa, 35(2), 351-367. https:// dx.doi.org/10.1590/S1517-97022009000200009 
Reis, E. J. F. B., Carvalho, F. M., de Araújo, T. M., Porto, L. A., \& Silvany Neto, A. M. (2005). Trabalho e distúrbios psíquicos em professores da rede municipal de Vitória da Conquista, Bahia, Brasil. Cadernos de Saúde Pública, 21(5), 1480-1490.

Ribeiro, J. L., \& Rodrigues, A. P. (2004). Questões acerca do coping: a propósito do estudo de adaptação do BriefCOPE. Psicologia, Saúde \& Doenças, 5(1), 3-15.

Roeser, R. W., Schonert-Reichl, K. A., Jha, A., Cullen, M., Wallace, L., Wilensky, R., Oberle, E. Thomson, K., Taylo, C., \& Harrison, J. (2013). Mindfulness training and reductions in teacher stress and burnout: Results from two randomized, waitlist-control field trials. Journal of Educational Psychology, 105(3), 787. https://doi.org/10.1037/a0032093

Salimzadeh, R., Hall, N. C., \& Saroyan, A. (2020). Stress, emotion regulation, and well-being among Canadian faculty members in research-intensive universities. Social Sciences, 9(12), 227. https://doi.org/10.3390/socsci9120227

Santiago, C. D., Wadsworth, M. E., \& Stump, J. (2011). Socioeconomic status, neighborhood disadvantage, and poverty-related stress: Prospective effects on psychological syndromes among diverse low-income families.
Journal of Economic Psychology, 32(2), 218-230. https://doi. org/10.1016/j.joep.2009.10.008

Santos, A. F. (2010). Determinantes psicossociais da capacidade adaptativa: um modelo teórico para o estresse [Doctoral Thesis]. Universidade Federal da Bahia. https://ri.ufs.br/ handle/riufs/1898

Selye, H. (1956). The stress of life. New York, Toronto, London: McGraw-Hill Book Company.

Silva, J., Morgado, J., \& Gomes, C. (2009). Satisfação, stress profissional e colaboração em docentes do $2^{\circ}$ e $3^{\circ}$ ciclo: que relações. In Actas do X Congresso Internacional GalegoPortuguês de Psicopedagogia (p. 1286-1301).

Skaalvik, E. M., \& Skaalvik, S. (2017). Teacher stress and teacher self-efficacy: Relations and consequences. In Educator stress (pp. 101-125). Springer International Publishing.

The American Institute of Stress. (2014). American's \#1 Health Problem. http://www.stress.org/americas-1-health-problem/

Soares, M. B. (2016). Análise do estresse ocupacional em docentes da Universidade Federal de Viçosa e suas interferências na qualidade de vida e suporte familiar [Master's Dissertation]. Universidade Federal de Viçosa. 